\title{
A integração ensino-serviço em Odontologia no Brasil
}

\author{
Jeusa Maria Faé*, Manoelito Ferreira Silva Junior**, Raquel Baroni de Carvalho***, Carolina Dutra \\ Degli Esposti****, Karina Tonini dos Santos Pacheco*****
}

* Mestre em Clínica Odontológica pela Universidade Federal do Espírito Santo. Cirurgiã-dentista, Prefeitura Municial de Vitória, ES

** Doutorando em Odontologia (Saúde Coletiva) na Faculdade de Odontologia de Piracicaba/Universidade Estadual de Campinas, Piracicaba-SP

*** Professora Associada do Departamento de Medicina Social da Universidade Federal do Espírito Santo, Vitória-ES

**** Professora Adjunta do Departamento de Medicina Social da Universidade Federal do Espírito Santo, Vitória-ES

\section{RESUMO}

O objetivo deste artigo foi discutir o processo histórico da integração ensino/serviço em Odontologia no Brasil. Foi realizada uma revisão de literatura a partir de um levantamento bibliográfico nas bases SciELO e LILACS utilizando as palavras-chave Integração ensino/serviço; Estágio curricular; Odontologia; Programa de Educação pelo Trabalho para a Saúde; PET-Saúde; Atenção primária à saúde; e Práticas profissionais, limitada a artigos publicados entre os anos de 1970-2014, em português. Também foi realizada uma pesquisa documental, contemplando as legislações existentes. A análise evidenciou que a integração ensino-serviço no Brasil, por muitas décadas, se deu de forma lenta, embora atualmente haja uma política de incentivo para favorecer esta integração. Foram identificadas experiências exitosas a partir da integração ensino-serviço em Odontologia, embora se destaque que ainda exista dificuldades e fragilidades, principalmente porque o sistema de saúde vigente no Brasil está em construção. Considera-se que os incentivos para a consolidação da parceria entre universidade e serviços de saúde devem ser mantidos e ampliados, com o objetivo de favorecer a formação profissional em Odontologia no aspecto mais amplo de saúde e trazer benefícios reais para os serviços de saúde.

Descritores: Saúde Pública. Serviços de Integração Docente-Assistencial. Odontologia. 


\section{INTRODUÇÃOO}

A integração ensino-serviço em saúde é entendida como um trabalho coletivo, pactuado e integrado entre universidade, por meio dos estudantes e dos docentes, e serviços de saúde, incluindo seus trabalhadores e gestores. Ademais, visa à qualidade da atenção à saúde individual e coletiva, bem como à qualidade da formação profissional e à satisfação dos trabalhadores em saúde $^{1,2}$. O objetivo precípuo de tal integração é tornar o Sistema Único de Saúde (SUS) uma rede de ensino-aprendizagem na prática do trabalho.

As estratégias de promoção da integração ensino-serviço na área da saúde ocorreram, inicialmente, para os cursos de Enfermagem e de Medicina, proporcionando avanços significativos em suas áreas, o que justificou a ampliação para outros cursos. A Odontologia, nesse contexto, inseriu-se tardiamente ${ }^{3}$. Embora realizada há algum tempo, essa articulação vem sendo alvo de reflexão em diferentes países ${ }^{4}$.

No Brasil, uma das atribuições do SUS é a formação de recursos humanos para a saúde. Nessa perspectiva, foram criadas as Diretrizes Curriculares Nacionais (DCN) para os cursos da área da Saúde, numa parceria entre o Ministério da Educação e Cultura (MEC) e o Ministério da Saúde (MS). Além disso, como forma de incentivo, o governo federal vem desenvolvendo importantes estratégias para qualificar a formação no campo da saúde ${ }^{5}$, tais como: a Política Nacional de Educação Permanente em Saúde, o Programa Aprender SUS, a Residência Multiprofissional em Saúde, o Programa Nacional de Reorientação da Formação Profissional em Saúde (Pró-Saúde) e o Programa de Educação pelo Trabalho para a Saúde (PET-Saúde) $)^{6-8}$.

Considerando a importância da integração ensino-serviço em saúde no processo de formação profissional acadêmica, de educação permanente dos profissionais da saúde e o processo de consolidação de todos os eixos envolvidos nesta articulação, é necessário conhecer e analisar seus antecedentes, estratégias e iniciativas, o que permite uma reflexão sobre a necessidade de sua qualificação e expansão. Para tanto, o objetivo deste artigo foi compreender e discutir, por meio de uma revisão da literatura, o processo histórico da integração ensino/serviço em Odontologia no Brasil.

\section{PERCURSO METODOLÓGICO}

Para fundamentar a análise e o contexto geral dos aspectos da integração ensino-serviço no Brasil, foi realizada uma revisão integrativa a partir de um levantamento bibliográfico nas bases de dados da Scientific Eletronic Library Online (SciELO) e Literatura Latino-Americana em Ciências da Saúde (LILACS), utilizando as palavras-chave Integração ensino/serviço; Estágio curricular; Odontologia; Programa de Educação pelo Trabalho para a Saúde; PET-Saúde; Práticas profissionais, com publicações entre os anos de 1970-2014, em português.

Também foi realizada pesquisa documental, contemplando a legislação referente à integração ensino-serviço em Odontologia no Brasil.

\section{RESULTADOS}

\section{Formação profissional em Odontologia}

A formação na área da Saúde no Brasil, por muito tempo, foi influenciada pelo modelo flexneriano, publicado em 1910 nos Estados Unidos, que versava sobre escolas médicas com base na qualidade técnica, enfatizando a formação de uma elite profissional. Esse modelo transformava problemas de origem social, que exigiam soluções políticas, em problemas da ciência, cujas soluções eram eminentemente técnicas. $\mathrm{O}$ ensino odontológico brasileiro assumiu características desse modelo, com relação, por exemplo, à separação entre a docência, a prestação de serviços e a pesquisa, à estruturação de disciplinas por especialidades odontológicas, centrado na difusão de tecnologia sofisticada, ao ensino exclusivo nos serviços das escolas, desconhecendo os serviços públicos externos, à relação professoraluno autoritária e paternalista e à ênfase na pesquisa biológica 9 .

Esse modelo de formação influenciou a for- 
ma de cuidado à saúde bucal no Brasil, excludente e incapaz de atender às reais necessidades da população $^{10}$. Entre as décadas de 1920 e 1940, a lógica dos serviços odontológicos era livre demanda, ofertados pelo Estado em centros urbanos, com prática pouco resolutiva. Nos anos 1950, foi implantado, pelos Serviços Especiais de Saúde Pública (SESP), o sistema incremental, cujos serviços eram curativos e ofertados somente aos escolares. Surgiram, também, outras propostas como a Odontologia Sanitária Social, a Simplificada e a Integral, com ações que se restringiam à fluoretação das águas de abastecimento público. No final da década de 1970, a Odontologia simplificada ganhou notoriedade por ter menor custo e maior cobertura. Já no final da década de 1980, o Programa Inversão da Atenção surgiu em decorrência das críticas ao sistema incremental. Esse modelo contrariou as ações curativas e buscou estabilizar o meio bucal pela eficácia dos meios preventivos ${ }^{11}$. Dessa forma, ficou clara a falha do modelo flexneriano em atender às necessidades da população e em atuar sobre os determinantes sociais, apesar dos evidentes avanços técnicos.

A crise internacional do petróleo, em 1973, gerou, no Brasil, crise social e, como consequência, a crise da previdência. Tal crise estimulou o Movimento pela Reforma Sanitária Brasileira, que buscou sintonizar a política nacional de saúde às discussões internacionais da época, sobre as condições de saúde e as formas de organização do cuidado. Os conceitos trazidos pela Conferência de Alma Ata ${ }^{12}$ e pela Carta de Ottawa $^{13}$, contribuíram para a definição constitucional de que a saúde é resultante das condições de vida e que é parte das diligências do Estado identificar e minimizar os riscos por meio de ações de saúde pública.

Criou-se, a partir do referido contexto, o SUS, incluído no relatório da VIII Conferência Nacional de Saúde, em 1986, e inserido em artigos na Constituição Nacional de 1988. Em 1990, com a aprovação das Leis Orgânicas da Saúde, nº 8.080 e $\mathrm{n}^{\circ} 8.142$, de 1990, o SUS foi regulamentado.
Essas leis detalharam o funcionamento do sistema e trouxeram elementos que avançaram no debate sobre a intrínseca associação entre as estruturas de formação e as de incorporação dos profissionais no mundo do trabalho. Dessa forma, o SUS também passou a ser considerado ordenador da formação profissional ${ }^{14}$.

Visando reorganizar a Atenção Básica no Brasil, foi proposto, em 1994, o Programa Saúde da Família (PSF), buscando a inversão do modelo assistencial que, até então, era biomédico e restrito à clientela reduzida, para uma abordagem com ênfase na atenção primária e partindo do núcleo familiar e da noção de território enquanto espaço social. A Odontologia não foi inserida na lista de profissões que prioritariamente contribuiriam com a mudança desse modelo.

Entretanto, a partir de 1995, importantes mudanças foram realizadas nos currículos de graduação em Odontologia, a partir da criação da Lei de Diretrizes e Bases da Educação Nacional (LDB) $\mathrm{n}^{\mathrm{o}}$ 9.394/96 ${ }^{15}$. A referida lei trouxe modificações significativas para a educação brasileira, envolvendo a reforma universitária em curso e nela o estabelecimento de novas condições concernentes à organização institucional, à autonomia acadêmica, ao compromisso social do ensino, à flexibilidade curricular e à avaliação das condições dos cursos de graduação ${ }^{15}$. Outra importante alternativa de inovação no ensino, orientada pela LDB, foi a substituição do currículo mínimo pelas Diretrizes Curriculares Nacionais (Parecer do CNE/CES no 776 de 31/12/1997) para a organização dos cursos de graduação de profissões da área de saúde ${ }^{16}$.

Somente em 2001, a Odontologia foi inserida na lógica do PSF, num contexto de dívida assistencial expressiva. No entanto, a implantação da equipe de saúde bucal (ESB), como projeto de reorientação e organização dos serviços e das práticas odontológicas, evidenciou o descompasso entre o ensino da Odontologia e a necessidade de saúde bucal da população brasileira. Foi constatado que o perfil de formação dos cursos de Odontologia ainda não estava suficientemente 
adequado para um trabalho na perspectiva da saúde como um produto social e, tampouco, para o cuidado integral e equânime, princípios fundamentais do SUS ${ }^{10,17}$.

Com o intuito de modificar essa realidade, foram implantadas as novas DCN para os cursos de graduação em Odontologia, aprovadas em 2002, através da Resolução CNE/CES nº 03 de 19/02/2002. O objetivo era que o currículo permitisse a construção de um perfil acadêmico e profissional com competências, habilidades e conteúdos, dentro de perspectivas e abordagens contemporâneas de formação pertinentes e compatíveis com referenciais nacionais e internacionais ${ }^{6}$. Isso foi pensado a partir de um processo histórico e não uma decisão autoritária do governo, levandose em consideração os interesses e as necessidades sociais da população brasileira e do profissional $^{17,18}$.

Atualmente, a prática educativa humanizada na área da Saúde inclui os estudantes no processo de construção da cidadania, comprometida e integrada à realidade social e epidemiológica, às políticas sociais e de saúde e oportunizando a formação profissional contextualizada e transformadora. Assim, as importantes mudanças curriculares após a implantação das DCN vêm ao encontro dessa prática ética, política e social da Odontologia ${ }^{9}$.

Para atender às DCN, as instituições de ensino superior da área da saúde têm desenvolvido atividades extramurais como parte integrante de seus projetos pedagógicos. Diversos estudos ${ }^{19-21}$ mostraram a efetividade dessas atividades, gerando otimistas perspectivas de inovação e concretização no tocante à integração ensinoserviço, e de forma geral, demonstram experiências que favorecem a formação profissional para o trabalho no SUS.

\section{A integração ensino-serviço em Odontologia}

Marcos históricos nortearam as discussões referentes à integração ensino-serviço em Odontologia no Brasil. Entre as décadas de 1950 e 1960, os cursos da área de Saúde no Brasil come- çaram a criar serviços em que a função assistencial era menos importante do que o suporte que eles ofereceriam às atividades de ensino. Durante a década de 1960, começou-se a questionar sobre a organização e os princípios sobre os quais ela estava assentada. Dentre esses princípios, pode-se citar a cátedra, o isolamento das faculdades, a multiplicidade das disciplinas, a hierarquização rígida, as formas de relação com a sociedade, e o papel social que desempenhava, dentre outros. No ano de 1968, houve uma reforma universitária, extinguindo a cátedra e criando departamentos e institutos. Já na década de 1970 , no intuito de prestar serviços à comunidade, junto com o ensino e a pesquisa, surgiram os serviços de extensão da universidade. A partir dessa década, muitas mudanças políticas, institucionais e legais ocorreram nos cenários da educação e da saúde ${ }^{3,22}$.

Entre os anos de 1985 e 1997, um dos projetos importantes promovidos pela Organização Pan-Americana de Saúde (OPAS), em parceria com o Ministério da Saúde do Brasil, foi o Projeto Integração Docente-Assistencial $(\text { IDA })^{2}$. Esse foi um projeto para a formação de todas as categorias profissionais da área da saúde, mediante um novo processo de ensinoaprendizagem, com vivências práticas na realidade concreta para o atendimento das necessidades da população, integração interinstitucional e mudanças no currículo das faculdades ${ }^{3}$. Em 1996, foi criado o Projeto "Uma Nova Iniciativa" (UNI) para a formação profissional em saúde, o qual incorporou as dimensões da multiprofissionalidade, da interdisciplinaridade e da participação popular. Mais tarde, juntos, esses projetos constituíram a Rede UNI IDA, ampliando a relação com o sistema de saúde ${ }^{2}$.

Em 2002, com a reestruturação das DCN em Odontologia vislumbrou-se que a integração ensino-serviço seria uma alternativa para a formação de um profissional com um perfil mais adequado ao SUS ${ }^{6}$. Possibilitaria o conhecimento das estruturas organizacional, administrativa, gerencial e funcional dos serviços públicos de saúde, a participação no atendimento à população, 
a compreensão das políticas de saúde bucal e do seu papel social, a participação dos alunos na dinâmica cultural, política e democrática da comunidade e a identificação das necessidades sociais, potencializando a criatividade e a autonomia nas propostas de soluções ${ }^{10,23}$.

Nesse contexto, surgiu a definição de estágio supervisionado para a Odontologia pela Associação Brasileira de Ensino Odontológico (ABENO), que vai ao encontro das DCN: “...o estágio supervisionado é o instrumento de integração e conhecimento do aluno com a realidade social e econômica de sua região e do trabalho de sua área...". "O aluno pode cumprilo em atendimentos multidisciplinares e em serviços assistenciais públicos e privados..." "17.

Para ampliar a experiência de estágio e vivência na área da saúde de forma interdisciplinar, foram criadas iniciativas políticas como a Vivências e Estágios na Realidade do Sistema Único de Saúde (VER-SUS/Brasil), em 2002, e o Programa de Interiorização do Trabalho (PIT), que fizeram parte de uma estratégia do MS junto ao movimento estudantil da área da Saúde, para aproximar os estudantes universitários dos desafios inerentes à consolidação do SUS, agregando diferentes cursos, incluindo a Odontologia ${ }^{24,25}$.

Também para fomentar a integração entre ensino e serviços de saúde, no ano de 2003, o MS procurou articular educação e regulação da força de trabalho nos serviços de saúde. O diálogo entre o MEC e outros órgãos possibilitou a criação da Secretaria de Gestão do Trabalho e da Educação em Saúde (SGTES), através do Decreto no 4.726, de 9 de junho de 2003. Essa secretaria passou a responder pela gestão federal da formulação de políticas orientadoras da formação, do desenvolvimento, da distribuição, da regulação e da gestão dos trabalhadores da saúde no SUS ${ }^{26}$.

Em 2005, a SGTES, em parceria com a Secretaria de Educação Superior (SESU) e o Instituto Nacional de Estudos e Pesquisas Educacionais Anísio Teixeira (INEP) do MEC, com apoio da OPAS, instituiu o Programa Nacio- nal de Reorientação da Formação Profissional em Saúde (Pró-Saúde), por meio da Portaria Interministerial MS/MEC $\mathrm{n}^{\circ} 2.101$, de 03 de novembro de $2005^{7}$, cujo objetivo foi a integração ensino-serviço, visando à reorientação da formação profissional, através de uma abordagem integral do processo saúde-doença com ênfase na Atenção Básica. Contemplou, inicialmente, os cursos de graduação de Enfermagem, Medicina e Odontologia. O programa foi ampliado através da Portaria Interministerial MS/MEC no 3019, de 27 de novembro de 2007, na qual os 14 cursos de graduação da área da saúde foram contemplados ${ }^{27}$.

Nesse contexto, também foi criado o Programa de Educação pelo Trabalho para a Saúde (PET-Saúde), através da Portaria Interministerial MS/MEC no 1.802, de 26 de agosto de 2008, inspirado no Programa de Educação Tutorial $(\mathrm{PET})^{28}$. A Portaria Interministerial MS/MEC $\mathrm{n}^{\circ}$ 421, de 03 de março de 2010, estabeleceu orientações e diretrizes técnico-administrativas para a execução do programa. O mesmo possui como pressuposto a educação pelo trabalho, oportunizando aos acadêmicos dos cursos de graduação em saúde, inclusive da Odontologia, a vivência do trabalho multidisciplinar nos serviços do SUS $^{29}$.

Já a Portaria Interministerial MS/MEC $\mathrm{n}^{\mathrm{o}}$ 4.279, de 30 de dezembro de 2010, estabeleceu diretrizes para a organização da Rede de Atenção à Saúde no âmbito do SUS, tendo, como uma de suas estratégias, ampliar o Pró-Saúde e o PETSaúde para todas as instituições de ensino superior, visando à mudança curricular e à formação de profissionais com perfil voltado às necessidades de saúde da população ${ }^{30}$.

\section{Experiências da integração ensino-serviço em Odontologia no Brasil}

Algumas experiências exitosas dessas políticas têm sido relatadas na literatura ${ }^{31-35}$. A experiência de integração de graduandos, pósgraduandos, docentes e serviços de saúde costuma ser positiva e enriquecedora para todas as partes envolvidas. A vivência prática dá sentido e signifi- 
cado quando integrada aos conhecimentos adquiridos. Além disso, os acadêmicos sentem-se, durante as atividades extramuros, mais bem preparados para atuar na comunidade, com vistas à atenção integral e mais humanizada ao paciente. Por outro lado, uma das dificuldades apontadas foi a falta de um projeto político-pedagógico consistente que favoreça atuação multiprofissional.

A experiência da Faculdade de Odontologia de Piracicaba (FOP/Unicamp) com auxílio do PróSaúde, no ano de 2008, possibilitou a inserção do aluno de graduação no contexto da ESF, através de um estágio extramuros nas Unidades de Saúde da Família (USF) de Piracicaba-SP. Depois de passarem dois anos no serviço, os alunos afirmaram ter compreendido o funcionamento do SUS e o benefício para comunidade com os projetos implantados pela parceria entre a FOP/Unicamp e a USF ${ }^{31}$.

$\mathrm{O}$ projeto de Vivências Interdisciplinares e Multidisciplinares (VIM) da Universidade Comunitária da Região de Chapecó (UnoChapecó) é um esforço dos cursos de Ciências da Saúde da universidade com a Secretaria da Saúde de Chapecó-SC, que teve suas atividades aprovadas no Pró-Saúde. De acordo com a vivência realizada, destacou-se o relato das expectativas dos estudantes: interesse pelo conhecimento da realidade do SUS, citado como principal área/espaço de atuação dos estudantes enquanto futuros profissionais; possibilidade de associação entre a teoria e a prática; estímulo à participação; oportunidade de interagir com profissionais da rede de atenção, comunidade e outras áreas do conhecimento. Essa experiência, possibilitou compartilhamento dos saberes através do reconhecimento da realidade e enfrentamento das possíveis situações do cotidiano. Dessa forma, através do processo de socialização, as práticas ganharam sentido e significado quando estão integradas ao conhecimento ${ }^{32}$.

Oliveira-Sobrinho et al..$^{33}$ descreveram a experiência da equipe de trabalho do PET-Saúde da Universidade Estadual de Montes Claros
(Unimontes) e dentre as ações exercidas, destacaram-se: realização interdisciplinar de grupos de educação em saúde, visitas domiciliares e atendimento clínico. A maior dificuldade apresentada foi à falta de um projeto políticopedagógico consistente que favorecesse a atuação multiprofissional.

A experiência do PET-Saúde da Universidade Estadual de Feira de Santana (UEFS), implantado em 2009, apontou um processo de intenso aprendizado na realização de ações interdisciplinares no âmbito da atenção básica, com o objetivo de contemplar o tênue equilíbrio entre as demandas de saúde da população e as possibilidades do atendimento ${ }^{34}$.

Gonçalves et al. ${ }^{35}$ descreveram a experiência do curso de Odontologia da Universidade Federal do Espírito Santo (Ufes) no Programa PET-Saúde, implantado em 2010. Através do processo de reorientação do ensino, foi observado que os acadêmicos que vivenciaram atividades extramuros estão mais bem preparados para atuar na comunidade, sobretudo em serviços de saúde, por terem tido a oportunidade do convívio em diferentes realidades econômicas e culturais da população. Além disso, o espírito de equipe e a capacidade de troca de experiências entre os acadêmicos e os profissionais do serviço proporcionavam uma atenção integral e mais humanizada do paciente.

\section{Avanços e desafios da integração ensino-serviço para a formação em Odontologia no Brasil}

A integração ensino-serviço de saúde, especialmente em Odontologia, tem sido buscada e aprimorada há várias décadas, visando à qualificação da formação profissional de acordo com a realidade do mundo do trabalho. Até a década de 1990, as mudanças ocorreram lentamente e só tiveram maior destaque a partir das DCN de 2002 e da consequente reestruturação dos projetos pedagógicos dos cursos de Odontologia. Ainda no sentido de fomentar a integração ensinoserviço, foram desenvolvidos programas em conjunto pelo MS e pelo MEC, primeiramente 
através do Pró-Saúde, seguido do PET-Saúde. Essas estratégias foram fortalecidas por diversos editais, tais como o incentivo para o PETEstratégia de Saúde da Família e as redes de atenção, em 2010, o edital conjunto Pró-Saúde e PET-Saúde, em 2011, e o PET-Redes de Atenção, em 2013, contemplando propostas de políticas e de prioridades do MS.

As referidas estratégias têm induzido a mudança curricular, e juntas, vêm apresentando avanços consideráveis para o campo da Odontologia, tais como: melhoria da articulação entre o sistema de ensino e os serviços de saúde; melhoria da qualidade da atenção à saúde e da formação profissional, inclusive na visão dos alunos; qualificação dos trabalhadores no serviço; e melhoria da gestão e contribuição para o fortalecimento e consolidação das políticas públicas de saúde $\mathrm{u}^{3,19-21,31-36}$. No entanto, é preciso que as universidades e os serviços de saúde busquem juntos, garantir a sustentabilidade dessas ações na ausência de editais específicos, mantendo as conquistas e avançando em sua qualificação.

A utilização da rede de serviços públicos como espaço de ensino-aprendizagem é imprescindível para a formação profissional, sendo necessário assumir que para aprender saúde é preciso participar dos espaços onde se faz saúde ${ }^{37}$. No entanto, é oportuno destacar que o cenário de atuação dos estudantes não pode se limitar às unidades de saúde, que muitas vezes possuem ação restrita à demanda da população, uma vez que o estudante necessita ter uma visão ampla da realidade local. Sendo assim, outros cenários são importantes no processo ensino-aprendizagem, tais como: espaços comunitários, escolas, domicílios e conselhos de saúde ${ }^{37}$.

O conhecimento da realidade social pode ser limitado caso o curso de Odontologia seja pautado somente em disciplinas de clínica integrada intramuros no final do curso, visando à realização de todos os procedimentos aprendidos ${ }^{38}$. A DCN estabelece uma carga horária mínima para o estágio, entretanto não apresenta uma clareza em sua definição. Assim, deve-se estabelecer o que se considera estágio supervisionado, para que este não se torne apenas uma mudança de cenário, sem haver real mudança das práticas e inserção dos alunos no contexto social da comunidade assistida.

Nesse sentido, a inserção dos alunos de graduação na realidade dos serviços, no contexto do SUS, precisa ir além de uma capacitação técnica, mas também contribuir para a construção de seu senso crítico sobre suas atividades profissionais. Apesar dos avanços observados, também existem dificuldades e limitações para a consolidação da articulação ensino-serviço, que precisam ser superadas. Destacam-se dentre elas: formação acadêmica da maioria dos docentes e profissionais em atuação no serviço com ênfase no biologicismo; baixa adesão de docentes para a função de tutoria acadêmica; falta de valorização pelos gestores dos serviços de saúde do papel dos preceptores na formação; desigualdade na distribuição dos alunos nos serviços de saúde das diversas regiões brasileiras, devido a uma concentração dos cursos de Odontologia na Região Sudeste; e dificuldade para avaliar os benefícios para o ensino e para os serviços de saúde ${ }^{39-43}$.

Uma das dificuldades é a necessidade de superação do paradigma flexneriano na formação acadêmica, que na prática pode se refletir na intencionalidade da maioria dos acadêmicos em atuar no setor privado. Esse fato pode estar relacionado ao perfil profissional reforçado pela maioria dos professores, cujo ensino apresenta excelente qualidade científica, mas é pautado, tradicionalmente, em privilegiar aspectos técnicos da profissão. Observa-se, muitas vezes, os estudantes chegando ao serviço com a expectativa de melhorar suas habilidades clínicas, o que reduziria a função da integração ensino-serviço dentro dos objetivos que se propõe alcançar.

Outro problema na implantação do estágio extramuro nas universidades tem sido a adesão dos professores, pois depende da voluntariedade, do apoio institucional e da participação do quadro docente como um todo ${ }^{37}$. No entanto, a formação do docente da área da saúde, inclusive de Odontologia, apresenta excelente formação 
técnico-científica especializada, mas pouca ou insuficiente formação didático-pedagógica ${ }^{44}$. Para contribuir para a superação de tais obstáculos, a formação e a capacitação docente devem ser repensadas, sendo mais críticos e reflexivos, sintonizados não só com a técnica, mas também com a didática e a política em que a Odontologia está inserida $^{43}$

O professor não é mais o centro do processo pedagógico e a doença é substituída pela saúde como estrutura fundamental do processo de aprendizagem $^{45}$. Mais espaços precisam ser criados para a interlocução entre as diversas instituições envolvidas e seus respectivos atores ${ }^{46}$, garantindo que haja uma reflexão conjunta sobre a importância do SUS enquanto cenário para a formação e sobre como essa interação se dá no cotidiano do trabalho. Juntos, esses atores podem criar estratégias de ação e de avaliação, buscando qualificar e fortalecer esse processo.

Ademais, é desejável que o serviço e a universidade trabalhem com o estudante em uma visão mais abrangente, possibilitando $o$ conhecimento de todo o funcionamento da rede de serviços de saúde, integrando o estudante não apenas ao contexto da saúde bucal, mas sua integralidade. A escolha pela atuação no setor público, muitas vezes, só ocorre a partir da sua inserção no mercado de trabalho, onde o SUS evidencia-se como o maior empregador para a área da Odontologia no Brasil.

Ainda como possíveis soluções para minimização do descompasso existente na formação profissional e a necessidade real de saúde da população, sugere-se uma maior conscientização e compreensão sobre a importância dessa integração por parte do serviço, por meio, por exemplo, de capacitações para o processo de preceptoria. A resistência dos profissionais muitas vezes justifica-se pela falta de infraestrutura, ambientes inapropriados, falta de tempo, prejuízo no serviço pelas mudanças no processo de trabalho e identificação de suas fragilidades pelos alunos, e para isso é imprescindível que o serviço esteja preparado física e organizacionalmente para receber os acadêmicos, apoiando a atuação dos preceptores. Além disso, é preciso garantir incentivos e valorização dos profissionais envolvidos através de políticas públicas mais consistentes e sistemáticas que articulem a integração ensinoserviço em um olhar ampliado da saúde, e possibilitar meios de avaliação dos seus ganhos e benefícios. Também deve haver uma melhor apropriação da temática pelos usuários, foco de todos esses esforços, a partir, por exemplo, de sua discussão nos conselhos de saúde.

Entende-se que a integração ensino-serviço se configura como um caminho sem volta, pois além de necessária à formação profissional acadêmica em Odontologia, mudando o foco do modelo biomédico, efetiva-se hoje como uma articulação que contribui e fortalece os cenários das práticas de saúde, modificando os processos de trabalho.

\section{CONSIDERAÇÕES FINAIS}

Muitos avanços foram alcançados com o processo de articulação entre o ensino e o serviço em Odontologia no Brasil no que diz respeito à melhor preparação dos acadêmicos, principalmente a partir das mudanças nos projetos pedagógicos dos cursos de Odontologia preconizadas pelas DCN de 2002 e das políticas de incentivos a essa integração. Entretanto, considera-se que ainda é frágil e, portanto, há muito que se construir para se obter uma política consolidada. O desafio é transpor os obstáculos para qualificar o ensino no contexto das necessidades de saúde da população, fortalecendo o SUS em todos os níveis de atenção à saúde.

Para que essa integração alcance seus objetivos, é preciso que os atores envolvidos assumam de fato seus papeis e atuem fortalecendo cada um dos pilares de sustentação dessa engenhosa estratégia. É preciso que se enxerguem como complementares na formação dos profissionais da odontologia, pois é no dia a dia dos serviços que muitas teorias e discussões realizadas em sala de aula ganham cenários e sujeitos reais. 
É possível que no cotidiano dos serviços no SUS, os alunos melhorem suas habilidades práticas, nos diferentes níveis de complexidade. Mas estas precisam estar comprometidas com as prioridades de saúde pública, definidas segundo o diagnóstico das necessidades da população. É possível ainda que a formação profissional permita a compreensão, pelos alunos, que outros elementos estão envolvidos na complexidade do modelo de determinação social da saúde. Serviços e universidades têm, juntos, a responsabilidade pela formação dos futuros profissionais, e devem se comprometer na continuidade da construção de processos de ensino-aprendizagem realmente efetivos diante do que espera da formação em Odontologia no Brasil.

\section{ABSTRACT}

Dentistry's teaching-service integration in Brazil The aim of this study was to discuss historical process about the teaching/service integration in Dentistry in Brazil. A literature search was conducted in the SciELO and LILACS databases using the keywords Teaching/service integration; Curricular training; Dentistry; Education Program for Health at Work; PET-Health; Primary health care; Professional practices, limited to papers published from 1970 to 2014, in Portuguese. It was also included the policies and legislation related to the subject. The analysis showed that the integration of teaching and service in Brazil for many decades, was given slowly, although currently there is a policy of incentives to encourage this integration. Some successful experiences from the teaching-service integration in Dentistry was found, although there are still difficulties and weaknesses, mostly because the current healthcare system in Brazil is still under construction. It is considered that the incentives for the consolidation of the partnership between universities and health services should be maintained and expanded with the aim of promoting professional training in Dentistry in the broadest aspect of health and bring real benefits to health services.
Descriptors: Public Health. Teaching Care Integration Services. Dentistry.

\section{REFERÊNCIAS}

1. Albuquerque VS, Gomes AP, Rezende CHA, Sampaio MX, Dias OV, Lugarinho RM. A integração ensino-serviço no contexto dos processos de mudança na formação superior dos profissionais da saúde. Rev Bras Educ Med 2008; 32(3):356-62.

2. Ellery AEL, Bosi MLM, Loiola FA. Integração ensino, pesquisa e serviços em saúde: antecedentes, estratégias e iniciativas. Saúde Soc 2013; 22(1):187-198.

3. Marsiglia RG. Relação ensino-serviços: dez anos de integração docente assistencial (IDA) no Brasil. São Paulo: Hucitec, 1995. 135 p.

4. Feuerwerker LCM, Almeida MJ. Integração ensino/serviço: a experiência da Rede Unida. In: Negri B, Faria R, Viana ALDA (Org.). Recursos humanos em saúde: política, desenvolvimento e mercado de trabalho. Campinas: Unicamp/NEPP, 2002, p. 161-86.

5. Morita MC, Haddad AE, de Araújo ME. Perfil atual e tendências do cirurgião-dentista brasileiro. Maringá: Dental Press, 2010.

6. Brasil. Resolução CNE/CES nº. 3, de 19 de fevereiro de 2002. Institui as Diretrizes Curriculares Nacionais do Curso de Graduação em Odontologia. Brasília 2002.

7. Brasil. Portaria interministerial n. 2.101, de 3 de novembro de 2005. Institui o Programa Nacional de Reorientação da Formação Profissional em Saúde - Pró-Saúde - para os cursos de graduação em Medicina, Enfermagem e Odontologia. Brasília 2005.

8. Brasil. Ministério da Saúde. Ministério da Educação. Programa Nacional de Reorientação da Formação Profissional em Saúde - Pró-Saúde: objetivos, implementação e desenvolvimento potencial. Brasília: Ministério da Saúde, 2009. 88p.

9. Pelissari LD, Basting RT, Flório FM. Vivência da realidade: o rumo da saúde para a odontologia. Rev ABENO 2004; 5(1):32-9. 
10. Saliba NA, Saliba O, Moimaz SAS, Garbin CAS, Arcieri RM, Lolli LF. Integração ensino-serviço e impacto social em cinquenta anos de história da saúde pública na Faculdade de Odontologia da Universidade Estadual paulista Júlio de Mesquita Filho. RGO 2009; 57(4):459-65.

11. Nickel DA, Lima FG, Silva BB. Modelos assistenciais de saúde bucal no Brasil. Cad Saúde Pública 2008; 24(2):241-6.

12. Organização Mundial de Saúde. Declaração de Alma-Ata. Conferência Internacional sobre cuidados primários de saúde. Alma-Ata: WHO, 1978. Acesso em: 13 mar. 2014. Disponível em: http://www.opas.org.br/cole tiva/uploadArq/Alma-Ata.pdf

13. Organização Mundial de Saúde. Carta de Ottawa. Primeira Conferência Internacional sobre promoção da saúde. Ottawa: WHO, 1986. Acesso em: 21 mar. 2014. Disponível em: http://www.opas.org.br/promocao/upload Arq/Ottawa.pdf

14. Brasil. Lei $n^{\circ} 8.080$, de 19 de setembro de 1990. Dispõe sobre as condições para a promoção, proteção e recuperação da saúde, a organização e o funcionamento dos serviços correspondentes e dá outras providências. Brasília 1990.

15. Brasil. Lei $n^{\circ} 9.394$, de 20 de dezembro de 1996. Estabelece as diretrizes e bases da educação. Brasília 1996.

16. Costa RKS, Miranda FAN. Sistema Único de Saúde e da Família na formação acadêmica do enfermeiro. Rev Bras Enferm 2009; 62 (2):300-4.

17. Carvalho ACP, Kriger L (Org.). Educação odontológica. São Paulo: Artes Médicas, 2006.

18. Senna MIB, Lima MLR. Diretrizes curriculares nacionais para o ensino de graduação em odontologia: uma análise dos artigos publicados na revista da ABENO, 2002-2006. Arq Odontol 2009; 45(1): 30-6.

19. Moimaz SAS, Saliba NA, Garbin CAS, Zina LG, Furtado JF, Amorin JA. Serviço extra- muro odontológico: impacto na formação do profissional. Pesqui Bras Odontopediatria Clín Integr 2004; 4(1):53-7.

20. Werneck MAF. Internato em saúde coletiva: a disciplina do estágio supervisionado em odontologia como espaço pedagógico: a possibilidade de uma nova práxis na graduação, na UFMG. In: Botazzo C, Oliveira MA (Org.). Atenção básica no Sistema Único de Saúde: abordagem interdisciplinar para os serviços de saúde bucal. São Paulo: Páginas \& Letras Editora e Gráfica, 2008, p. 181-93.

21. Pinheiro FMC, Nóbrega-Therrien SM, Almeida MEL, Almeida MI. A formação do cirurgião-dentista no Brasil: contribuições de estudos para a prática da profissão. RGO 2009; 57(1):99-106.

22. Brehmer LCF, Ramos FRS. Experiências de integração ensino-serviço no processo de formação profissional em saúde: revisão integrativa. Rev Eletrônica Enferm 2014; 16(1):228-37.

23. Melo TAF, Kunert GG, Limongi O, Matos AP, Gardelin VA. Centro de Especialidades Odontológicas (CEO): uma avaliação qualitativa na perspectiva dos alunos participantes. Stomatos 2009;15(29):32-7.

24. Oliveira MC. Os modelos de cuidados como eixo de estruturação de atividades interdisciplinares e multiprofissionais em saúde. Rev Bras Educ Med 2008; 32(3):347-55.

25. Mendes FMS, Fonseca KA, Brasil JA, Dalbello-Araújo M. VER-SUS: Relato de Vivências na Formação de Psicologia. Psicol Ciênc Prof 2012; 32(1):174-87.

26. Brasil. Ministério da Saúde. Secretaria Executiva. Secretaria de Gestão do Trabalho e da Educação na Saúde. Glossário temático: gestão do trabalho e da educação na saúde. $2^{\circ}$ ed. Brasília: Ministério da Saúde, 2012. 44p.

27. Brasil. Portaria interministerial n 3.019 de 26 de novembro de 2007. Dispõe sobre o Programa Nacional de Reorientação da Formação Profissional em Saúde - Pró-Saúde - para os cursos de graduação da área da 
saúde. Brasília 2007.

28. Brasil. Portaria Interministerial $\mathrm{n}^{\circ} 1.802$, de 26 de agosto de 2008. Institui o Programa de Educação pelo Trabalho para a Saúde - PET Saúde. Brasília 2008.

29. Brasil. Portaria Interministerial $n^{\circ} 422$, de 3 de março de 2010. Estabelece orientações e diretrizes técnico-administrativas para a execução do Programa de Educação pelo Trabalho para a Saúde - PET Saúde, instituído no âmbito do Ministério da Saúde e do Ministério da Educação. Brasília 2010.

30. Brasil. Portaria $n^{\circ} 4.279$, de 30 de dezembro de 2010. Estabelece diretrizes para a organização da Rede de Atenção à Saúde no âmbito do Sistema Único de Saúde (SUS). Brasília 2010.

31. Batista MJ, Gibilini C, Kobayashi HM, Ferreira LL, Gonçalo CS, Sousa MLR. Relato de experiência da interação entre universidade, comunidade e unidade de Saúde da Família em Piracicaba, SP, Brasil. Arq Odontol 2010; 46(3):144-51.

32. Stanga AC, Ferrão AC, Kleba ME. O VIM como experiência de interdisciplinaridade no processo de formação em saúde. 2013. In: Anais do Simpósio internacional sobre interdisciplinaridade no ensino, na pesquisa e na extensão - região sul (SIIEPE - SUL), 2013, Florianópolis. Florianópolis: EGC/ UFSC, 2013. Acesso em: 12 jul. 2014. Disponível em: http://www.siiepe.ufsc.br/wpcontent/uploads/2013/10/E-Stanga.pdf

33. Oliveira-Sobrinho TA, Medeiros CPP, Maia MR, Reis TC, Miranda LP, Costa PF. Integração acadêmica e multiprofissional no PET-Saúde: Experiências e desafios. Rev ABENO 2011; 11(1):39-42.

34. Rodrigues AAAO, Juliano IA, Melo MLC, Beck CLC, Prestes FC. Processo de Interação Ensino, Serviço e Comunidade: a Experiência de um PET-Saúde. Rev Bras Educ Med 2012; 36(1):184-92.

35. Gonçalves CM, Santos KT, Carvalho RB. O PET-Saúde como instrumento de reorientação do ensino em Odontologia: a experiência da Universidade Federal do Espírito Santo. Rev ABENO 2011; 11(2):27-33.

36. Moimaz SAS, Saliba NA, Garbin CAS, Zina LG. Atividades extramuros na ótica de egressos do curso de graduação em odontologia. Rev ABENO 2008; 8(1):23-9.

37. Morita MC, Kriger L. Mudanças nos cursos de Odontologia e a interação com o SUS. Rev ABENO 2004; 4(1):17-21.

38. Werneck MAF, Senna MIB, Drumond MM, Lucas SD. Nem tudo é estágio: contribuições para o debate. Ciênc Saúde Coletiva 2010; 15(1):221-31.

39. Werneck MAF, Lucas SD. Estágio supervisionado em odontologia: uma experiência da integração ensino/serviço de saúde bucal. Arq Centro Estudos Fac Odontol Univ Fed Minas Gerais 1996; 32(2):95-108.

40. Moysés SJ. Políticas de saúde e formação de recursos humanos em odontologia. Rev ABENO 2003; 4(1):30-7.

41. Silveira JLGC. Diretrizes Curriculares Nacionais para os cursos de graduação em odontologia: historicidade, legalidade e legitimidade. Pesqui Bras Odontopediatria Clín Integr 2004; 4(2):151-6.

42. Fernandes-Neto AJ, Carvalho ACP, Kriger L, Morita MC, Toledo OA. A trajetória dos cursos de odontologia no Brasil. In: Haddad AE (Org.). A trajetória dos cursos de graduação na Saúde: 1991-2004. Brasília: INEP/MEC, 2006, p. 381-409.

43. Carvalho RB, Costa TBC, Gomes MJ, Santos KT, Guerra SMG. Formação docente em odontologia no Brasil: sugestões de mudanças após as diretrizes curriculares nacionais. Rev Bras Pesqui Saúde 2010;12(4):39-44.

44. Baltazar MMM; Moyses SJ, Bastos CCBC. Profissão, docente de odontologia: o desafio da pós-graduação na formação de professores. Trab Educ Saúde 2010; 8(2):285-303.

45. Campos FE, Brenelli SL, Lobo LC, Haddad AE. O SUS como escola: a responsabilidade social com a atenção à saúde da população e 
com a aprendizagem dos futuros profissionais de saúde. Rev Bras Educ Med 2009; 33(4):513-4.

46. Henriques RLM. Interlocução entre ensino e serviço: possibilidades de ressignificação do trabalho em equipe na perspectiva da construção social da demanda. In: Pinheiro R, Mattos RA (Org.). Construção social da demanda. Rio de Janeiro: CEPESC/ ABRASCO; 2005.
Correspondência para:

Karina Tonini dos Santos Pacheco

e-mail: kktonini@yahoo.com.br

Departamento de Medicina Social, Universidade Federal do Espírito Santo.

Av. Marechal Campos, 1468, Maruípe

29040-090 Vitória, ES 